\title{
Massive cardiomegaly
}

\author{
Luisa María Charco-Roca, María Garví-López and Lorena Moreno-De la Rosa \\ Universidad de Castilla-La Mancha, Hospital General Universitario de Albacete; Centro de Salud de Villanueva de la Jara, Castilla-La Mancha, Spain
}

\begin{abstract}
Eighty-year old woman with a medical history of arterial hypertension, rheumatic valvular heart disease with mitral and aortic valve replacement, chronic atrial fibrillation and congestive heart failure dependent on domiciliary chronic oxygen for 17 daily hours. The reason for arrival to the hospital was a stroke of cardioembolic etiology.
\end{abstract}

KEY WORDS: Cardiomegaly. Biatrial enlargement. Chest radiograph.

Eighty-year-old woman with a history of arterial hypertension, rheumatic valvular heart disease with mitral and aortic valve replacement, chronic atrial fibrillation and congestive heart disease dependent on chronic oxygen support at home for 17 hours a day. The reason for arrival to the hospital was a stroke of cardioembolic etiology. On chest radiography, cardiomegaly with tracheal bifurcation horizontalization was observed (Fig. 1), an indirect sign of cardiac cavities dilation that can aid differential diagnosis with pericardial effusion.

The echocardiography of the patient showed severe dilatation of both atria and right ventricular dilatation with severely decreased right ventricular ejection fraction, as well as preserved left ventricular ejection fraction. Dilatation of both atria can be observed in the electrocardiogram as voltage and P-wave duration increase (higher than $2.5 \mathrm{mV}$ or $\mathrm{P}$ pulmonale), especially at V1 and lower leads.

The increase of both atrial cavities can occur as an unusual cause of massive cardiomegaly. The causes of biatrial enlargement include restrictive cardiomyopathy, rheumatic heart disease, isolated mitral incompetence and constrictive pericarditis. ${ }^{1}$ The clinical consequences of severe biatrial dilatation are derived from congestive heart failure and adjacent structures' compression; the most common manifestation is dyspnea. ${ }^{2}$

In most cases, a chest X-ray will be enough to detect cardiomegaly. Cardiac chambers specific enlargement can be recognized by changes in the cardiac contour, new or different interfaces with the

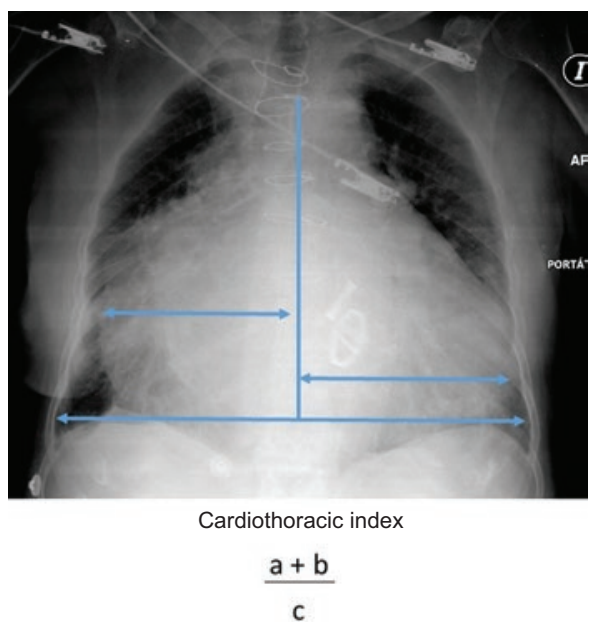

Figure 1. Portable anteroposterior chest $X$-ray. Cardiothoracic index of 0.8 .

adjacent lung or displacement of adjacent mediastinal structures. The cardiothoracic ratio or cardiothoracic index is the ratio between the longest cardiac horizontal diameter and the longest thoracic horizontal diameter (Fig. 1). Cardiothoracic index entails a simple calculation that helps to detect the cardiac silhouette enlargement and is considered to be normal when it is less than or equal to 0.5 .

\section{References}

1. Sethi $T$, Singh AP, Singla V, Singh $Y$. Biatrial enlargement: an unusual cause of massive cardiomegaly. BMJ Case Reports. 2013;2013.

2. Rogers WR, Wittels $B$. extreme bilateral atriomegaly; review of the literature and report of a case. Circulation. 1957;15:434-441.
Correspondence:

Luisa María Charco-Roca

E-mail: luisacharco@gmail.com
Date of reception: 07-05-2018

Date of acceptance: 08-05-2018

DOI: 10.24875/GMM.M19000217
Gac Med Mex. 2018;154:624-624

Contents available at PubMed www.gacetamedicademexico.com 